\title{
RF Characteristics of GaAs/InGaAsN/GaAs P-n-P Double Heterojunction Bipolar Transistors
}

\author{
A. G. Baca, ${ }^{*}$ P. C. Chang, N. Y. Li, ${ }^{* *}$ H. Q. Hou, ${ }^{* *}$ C. Monier, ${ }^{* * *}$ J. Laroche, ${ }^{* * *} \mathrm{~F}$ \\ Ren, ${ }^{* * *}$ and S. J. Pearton*** \\ *Sandia National Laboratories, P. O. Box 5800, MS-0603, Albuquerque, NM 87185-0603 \\ **Emcore Corporation, Albuquerque, NM 87123 \\ ***University of Florida, Gainsville, FL 32611
}



\begin{abstract}
We have demonstrated a P-n-P GaAs/InGaAsN/GaAs double heterojunction bipolar transistor (DHBT). The device has a low turn-on voltage $\left(V_{O N}\right)$ that is $0.27 \mathrm{~V}$ lower than in a comparable P-n-p AlGaAs/GaAs HBT. The device shows nearideal DC characteristics with a current gain $(\beta)$ greater than 45 . The high-speed performance of the device are comparable to a similar P-n-p AlGaAs/GaAs HBT, with $f_{T}$ and $f_{M A X}$ values are both approximately $12 \mathrm{GHz}$. This device may be suitable for low-power complementary HBT circuit applications, while the aluminum-free emitter structure eliminates issues typically associated with AlGaAs.
\end{abstract}

\section{INTRODUCTION}

The trend in portable electronics is to extend the battery lifetime without sacrificing the performance. One approach toward this goal is to reduce the operating voltages without compromising power added efficiency, making devices with lower turn-on voltages more desirable. For heterojunction bipolar transistors (HBTs), a lower bandgap $\left(E_{\mathrm{G}}\right)$ base reduces the tum-on voltage $\left(V_{O N}\right)$, and leads to greater efficiency at low-bias conditions. HBTs with InGaAs bases lattice matched to InP substrates offer one possibility that has not been adopted by commercial foundries due to substrate cost. concern over breakage, and possibly lack of 6" wafers. InGaAsN lattice matched to GaAs is a new material that has received a lot of attention lately [1-5]. Incorporating small amount of $I n$ and $N$ would result in a significantly reduced $E_{G}$ compared to GaAs, making it very suitable for low-power HBT applications. Recently we demonstrated both $\mathrm{N}-\mathrm{p}-\mathrm{N}$ and P-n-p InGaAsN HBTs [4-5]. The latter device used a AlGaAs emitter while the former used an InGaP emitter. Both the $\mathrm{N}-\mathrm{p}-\mathrm{N}$ and $\mathrm{P}-\mathrm{r}-\mathrm{P}$ InGaAsN HBTs show $\mathrm{V}_{\mathrm{ON}}$ values that are significantly lower than in the corresponding GaAsbased HBTs, showing the potential of InGaAsN based HBTs for low power applications.

The N-p-N HBT is of potential interest for wireless applications. The application of $\mathrm{P}-\mathrm{n}-\mathrm{P}$ HBTs would be in complementary applications, which have so far proven more difficult to realize in GaAs manufacturing than for the $\mathrm{Si}$ counterpart. Nevertheless, complementary GaAs-based HBTs should some day provide the same advantages to wireless technology as complementary bipolar BJTs do for analog applications today [6]. Apart from these practical applications, development of the P-n-P HBT with InGaAsN base material allows for some novel new devices due to the unique band alignments present with this material. In this work, we present a new P-n-P InGaAsN DHBT with a GaAs emitter. The Al-free design will simplify or eliminate many of the issues typically associated with AIGaAs.

\section{THEORY}

InGaAsN is a new material with unique band bowing properties [1] that has shown promise in optoelectronic applications [2-3]. The $E_{G}$ of $\mathrm{GaAs}$ is reduced as In is incorporated, while a compressive strain develops. On the other hand, by adding $N$ into GaAs, a tensile strain develops, while the $E_{G}$ is further reduced. By incorporating the proper amount of In and $\mathrm{N}$ into GaAs simultaneously, InGaAsN that is lattice matched to GaAs can be obtained. The $E_{G}$ of the
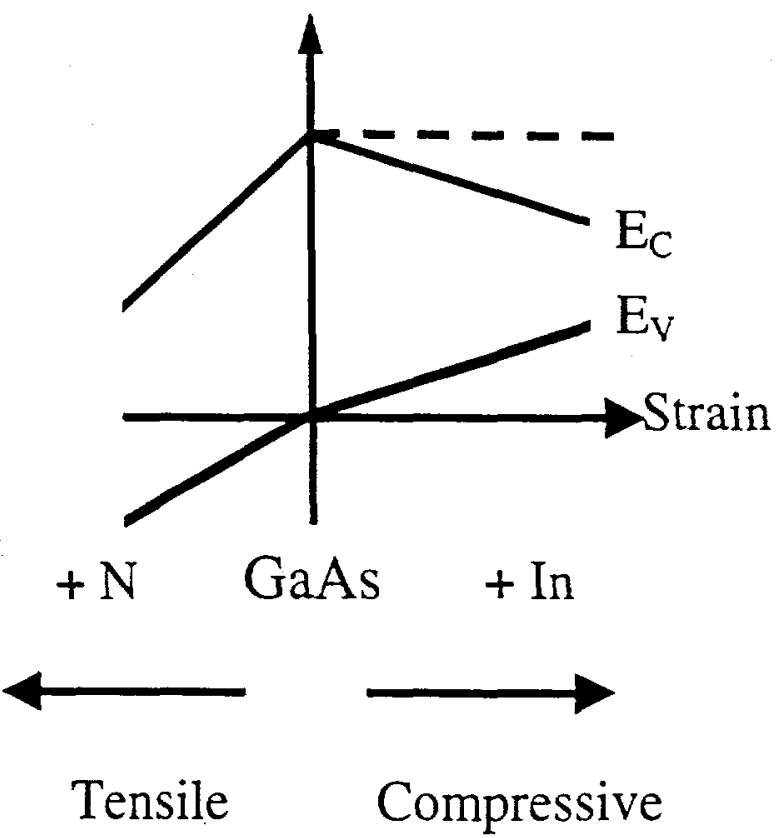

Figure 1: The effect on the band alignment of incorporating In and $\mathrm{N}$ into GaAs. 


\section{DISCLAIMER}

This report was prepared as an account of work sponsored by an agency of the United States Government. Neither the United States Government nor any agency thereof, nor any of their employees, make any warranty, express or implied, or assumes any legal liability or responsibility for the accuracy, completeness, or usefulness of any information, apparatus, product, or process disclosed, or represents that its use would not infringe privately owned rights. Reference herein to any specific commercial product, process, or service by trade name, trademark, manufacturer, or otherwise does not necessarily constitute or imply its endorsement, recommendation, or favoring by the United States Government or any agency thereof. The views and opinions of authors expressed herein do not necessarily state or reflect those of the United States Government or any agency thereof. 


\section{DISCLAIMER}

Portions of this document may be illegible in electronic image products. Images are produced from the best available original document. 
Table I : The layer structure of the P-n-P

$\mathrm{GaAs} / \mathrm{InGaAsN} / \mathrm{GaAs}$ DHBT.

\begin{tabular}{|c|c|c|c|}
\hline & Material & Thickness $[\AA]$ & Doping $\left[\mathrm{cm}^{-3}\right]$ \\
\hline & $p^{+} \mathrm{GaAs}$ & 3000 & $2.00 \mathrm{E}+19$ \\
\hline Emitter Layer & $p \mathrm{GaAs}$ & 700 & $2.00 \mathrm{E}+18$ \\
\hline Base Layer & $n$ In GaAsN & 1000 & $3.00 \mathrm{E}+18$ \\
\hline Collector Layer & $p^{-} \mathrm{GaAs}$ & 5000 & $3.00 \mathrm{E}+16$ \\
\hline & $p^{+} \mathrm{GaAs}$ & 7500 & $2.00 \mathrm{E}+19$ \\
\hline Substrate & & S. I. GaAs \\
\hline
\end{tabular}

resulting InGaAsN would be significantly lower because of the aggregate $E_{G}$ reduction from the incorporation of $N$ and In. The band alignment of the InGaAsN material system is illustrated in Figure 1 [1]. InGaAsN lattice matched to GaAs would have almost all of its $E_{G}$ reduction in the form of conduction band $\left(E_{C}\right)$ lowering, thus resulting in a large conduction band offset $\left(\Delta \mathrm{E}_{\mathrm{C}}\right)$ with negligible valence band offset $\left(\Delta E_{V}\right)$.

This band alignment is especially suitable for $\mathrm{P}-\mathrm{n}-\mathrm{p}$ HBT applications. The $\Delta E_{C}$ offset in an HBT is used to reject majority carrier electrons from the base from being injected back into the emitter. For P-n-p InGaAsN HBTs, the bandgap of the base can be reduced with nearly all of the change in bandgap available for the barrier to back conduction to the emitter. Theoretically larger current gain can therefore be attained in P-n-p InGaAsN HBTs. In practice, there will be other factors limiting current gain, such as defect associated recombination in the base.

In this work, we have investigated $\mathrm{In}_{0.03} \mathrm{Ga}_{0.97} \mathrm{As}_{0.99} \mathrm{~N}_{0.01}$ for P-n-P DHBTs. The InGaAsN used in this work is lattice matched to GaAs with an $E_{G}$ of approximately $1.2 \mathrm{eV}$, with almost $0.2 \mathrm{eV}$ of $\Delta \mathrm{E}_{C}$ when it is stacked next to GaAs. Since the $\Delta E_{C}$ is significant while $\Delta E_{V}$ is extremely small, GaAs can be used as the emitter and the collector material. Hole transport across the emitter-base and the base-collector junction can be achieved without resorting to any exotic junction grading designs. The GaAs collector would allow this device to take advantage of the larger $E_{G}$ of $G a A s$, thus allowing good breakdown voltage. In addition, the hole mobility in GaAs is almost 6 time better than in InGaAsN, thus permitting much improved collector characteristics. Similarly, GaAs is better than AlGaAs as the emitter material because it allows an aluminum-free structure, with improved material properties. AlGaAs is suspected of having impurity or defect centers that can enhance recombination and negatively impact reliability.

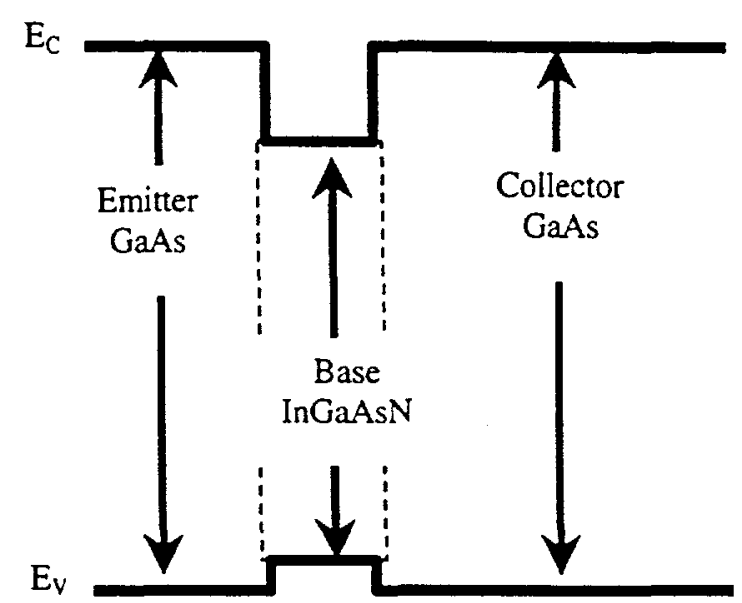

Figure 2: $\quad$ The band diagram of the $\mathrm{P}-\mathrm{n}-\mathrm{P}$ GaAs/nnGaAsN/GaAs DHBT.

AlGaAs/InGaAsN also has a small but significant $\Delta \mathrm{E}_{\mathrm{v}}$ comparable to that in $\mathrm{AlGaAs} / \mathrm{GaAs}$ that is a barrier to hole injection into the base. This barrier is not typically thought to cause any problems in conventional $\mathrm{P}-\mathrm{n}-\mathrm{p}$ HBTs, but its elimination may lead to some advantages under low voltage biasing conditions. A DHBT design of this type is unique in having no barriers to the desired current flow from emitter to collector, while maintaining a barrier to back injection in to the emitter. The GaAs/nnGaAsN/GaAs P-n-P DHBT structure is shown in Table I. The corresponding band diagram of this structure shown in Figure 2.

\section{EXPERIMENT}

The P-n-P DHBT shown in Table I was grown by an Emcore D180 turbodisk reactor. Trimethylindium. trimethylgallium, $100 \%$ arsine $\left(\mathrm{AsH}_{3}\right)$, and 1,1dimethylhydrazine (DMHy) were used as the In, Ga. As, and $\mathrm{N}$ precursors, respectively, for the growth of InGaAsN base layer. The indium and nitrogen compositions were determined by secondary ion mass spectroscopy and highresolution $x$-ray diffraction measurements. The doping concentrations in epilayers were confirmed with Polaron and Hall measurements. A comparable P-n-p AlGaAs/GaAs HBT structure was also grown for comparison purposes.

Both devices have been fabricated using a triple mesa process with emitter area of $3 \times 25 \mu \mathrm{m}^{2}$. All three mesa etching processes were performed by wet etching using $\mathrm{H}_{3} \mathrm{PO}_{4}: \mathrm{H}_{2} \mathrm{O}_{2}: \mathrm{H}_{2} \mathrm{O}$ as the etchant. Sputtered WSi served as the emitter metal, while evaporated PdGeAu and TiPtAu were used as the base and collector contact, respectively. A 4000 $\AA$ thick layer of $\mathrm{SiO}_{X} \mathrm{~N}_{Y}$ was deposited by ECR for device passivation. The devices are then tested by HP-4145 for device DC characteristics, and HP-8510 for device if characteristics. 


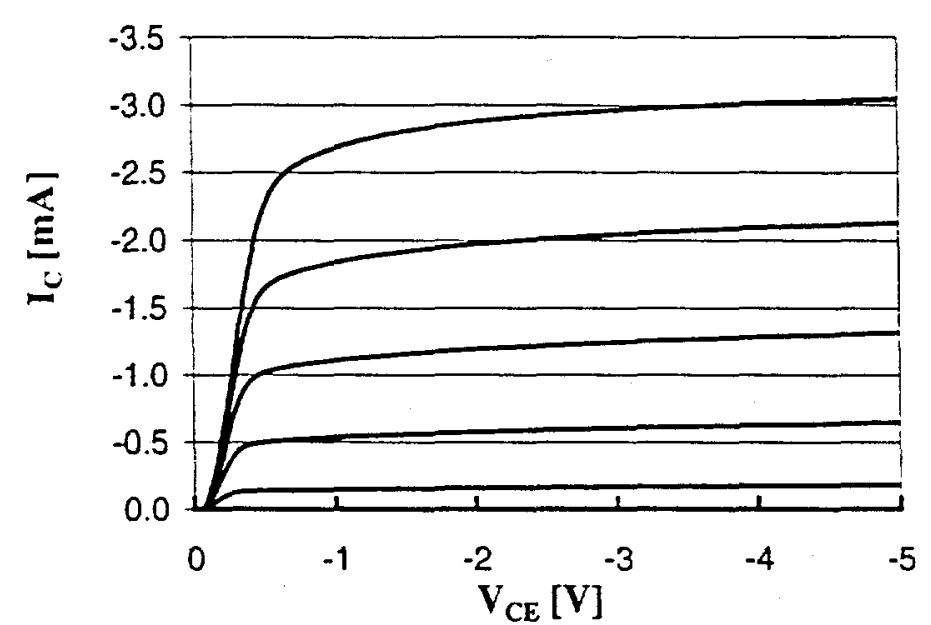

Figure 3 : The common emitter IV characteristics of the $3 \times 25 \mu \mathrm{m}^{2} \mathrm{P}-\mathrm{n}-\mathrm{P} \mathrm{GaAs} / \mathrm{InGaAsN} / \mathrm{GaAs}$ HBT. The base current varies from $20 \mu \mathrm{A}$ to $100 \mu \mathrm{A}$ at $20 \mu \mathrm{A} / \mathrm{step}$.

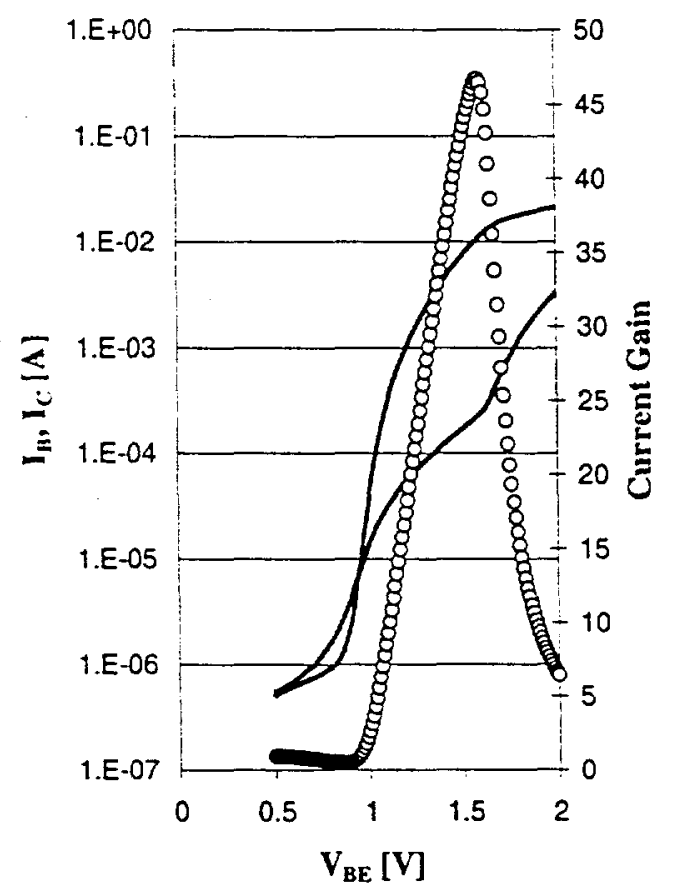

Figure 4: The Gummel plot of the $3 \times 25 \mu \mathrm{m}^{2} \mathrm{P}-\mathrm{n}-\mathrm{P}$ GaAs/InGaAsN/GaAs HBT. The B bias is set at 0 V.

\section{RESULTS}

The GaAs/InGaAsN/GaAs DHBT has a functional current gain $(\beta)$ that is greater than 45 , and the device has nearly ideal IV characteristics as shown in Figures 3 and 4. Compared to the P-n-p AlGaAs/GaAs HBT, a significantly reduced $\beta$ was observed, 45 compared to 130 . The baseemitter junction for GaAs/InGaAsN does have a reduced $\Delta E_{C}$

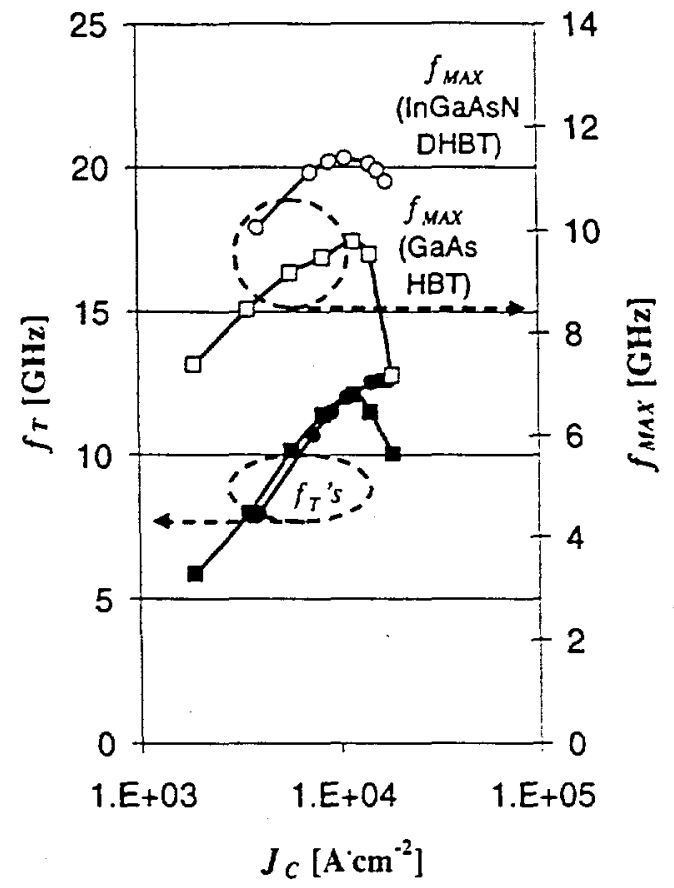

Figure $5:$ The $f_{\tau}$ and $f_{\text {MAX }}$ of the GaAs/nGaAsN/GaAs P-n-P HBT, and of the AlGaAs/GaAs P-n-p HBT.

compared to AlGaAs/GaAs. However, it is more likely that the $\beta$ difference is due to excess base recombination in InGaAsN compared to GaAs. In our earlier work, a AlGaAs/InGaAsN P-n-P DHBT showed lower $\beta$ than the AlGaAs/GaAs HBT in spite of a larger $\Delta E_{C}[7]$. Despite recent advances in the InGaAsN material, the crystal quality of the InGaAsN base is still inferior to that of a GaAs base, showing lower photoluminescence intensity, for example. However, the $V_{O N}$ of the InGaAsN DHBT is about $0.27 \mathrm{~V}$ lower than in the comparable GaAs HBT, and even slightly lower than the $0.25 \mathrm{~V}$ for a comparable AIGaAs/InGaAsN HBT reported previously [7]. The resulting offset voltage ( $\mathrm{V}_{\text {offsed }}$ of $0.06 \mathrm{~V}$ is also significantly lower than the $0.13 \mathrm{~V}$ observed in the GaAs HBT. These low voltage are an expected characteristic of the reduced $\mathrm{E}_{\mathrm{G}}$ in the base material, and from the near-ideal band alignment of the base-emitter and the base-collector junctions.

The $f_{T}$ of the P-n-P GaAs//nGaAsN/GaAs DHBT is about $12 \mathrm{GHz}$, comparable to that of a similar AlGaAs/GaAs P-n-p HBT. The $f_{\text {MAX }}$ of about $12 \mathrm{GHz}$ observed in the InGaAsN device, however, is almost $2 \mathrm{GHz}$ higher than in a similar GaAs based P-n-p HBT. The of characteristics of these devices are compared in Figure 5. These are excellent results considering that they are either comparable to or better than in the comparable AlGaAs/GaAs device. The comparable $f_{T}$ values are expected considering that the base layer constitute only a small portion of the total HBT structure, while the GaAs emitter actually provides better hole transport properties than in a AlGaAs emitter, thus the total transit time required for transport a hole thru the HBT structure is not significantly affected. The improved $f_{M A X}$ value, however, is 
somewhat surprising since the GaAs base was expected to be of better material quality than the InGaAsN, but may be due to the advantage of a GaAs emitter over AlGaAs and an improved base-emitter junction.

\section{CONCLUSION}

In conclusion, we have demonstrated a GaAs/InGaAsN/GaAs P-n-P DHBT that has shown near-ideal DC characteristics with a functional $\beta$ of 45 , while its of characteristics are comparable or better than in a similar AlGaAs/GaAs HBT. The GaAs emitter in this design eliminates the problems associated with AlGaAs emitters. And the reduced $V_{\text {ON }}$ of $0.27 \mathrm{~V}$ makes it very useful for lowvoltage complementary electronics that can take advantage of the maturing GaAs foundries.

\section{ACKNOWLEDGEMENT}

The authors would like to acknowledge the device fabrication by Geraldine Lopez, Melissa Cavaliere, and Andrea Ongstad. Sandia is a multiprogram laboratory operated by Sandia Corporation, a Lockheed Martin Company, for the United States Department of Energy under Contract DE-AC04-94AL85000.

\section{REFERENCES}

[1] M. Kondow, S. A. Nakatsuka, T. Kitatani, Y. Yazawa, and M. Okai, "Room temperature pulsed operation of GalnNAs laser diodes with excellent high-temperature performance," Jpn. J. Appl. Phys., Part I, vol. 35, pp. 5711-5713, 1996.
[2] N. Y. Li, C. P. Hains, K. Yang, J. Lu, J. Cheng, and P. W. $\mathrm{Li}$, "Organometallic vapor phase epitaxy growth and optical characteristics of almost $1.2 \mu \mathrm{m}$ GalnNAs threequantum-well laser diodes," Appl. Phys. Lett., vol. 75, pp. 1051-1053, 1999.

[3] H. Q. Hou, K. C. Reinhardt, S. R. Kurz, J. M. Gee, A. A. Allerman, B. E. Hammons, P. C. Chang, and E. D. Jones, Proc. of the $2^{\text {nd }}$ World Conference and Exhibition on Photovoltaic Solar Energy Conversion, Edited by J. Schmid (The European Comission, Directorate General Joint Research Centre, Environment Institute, Renewal Energy Unit, Ispra, VA, Italy), pp. 3600-3603, 1998.

[4] P. C. Chang, A. G. Baca, N. Y. Li, X. M. Xie, H. Q. Hou. E. Armour, "InGaP/InGaAsN/GaAs NpN doubleheterojunction bipolar transistor," Applied Physics Letters, vol. 76, pp. 2262-2264, 2000.

[5] P. C. Chang, A. G. Baca, N. Y. Li, P. R. Sharps, H. Q. Hou, J. R. Laroche, and F. Ren, "InGaAsN/AlGaAs P-n-p heterojunction bipolar transistor," Applied Physics Letters, vol. 76, pp. 2788-2790, 2000.

[6] D. Sawdai, and D. Pavlidis, "Push-pull circuits using $n-p-n$ and p-r-p InP-based HBT's for power amplification," IEEE Transactions on Microwave Theory and Techniques, vol. 47, p. 1439-1448, 1999.

[7] P. C. Chang, A. G. Baca, N. Y. Li, H. Q. Hou, J. R. Laroche, and F. Ren, "Device Characteristics of the PnP AlGaAs/InGaAsN GaAs Double Heterojunction Bipolar Transistor," Proc. Electrochemical Society Meeting, vol. PV2000-1, (The Electrochemical Society, Pennington, NJ) pp. $305-312,2000$. 